\title{
Responsiveness of the Korean Version of the Voice Activity and Participation Profile (K-VAPP) after Surgical Intervention
}

\author{
Seung Jin Lee ${ }^{\mathrm{a}}$, Sung-Eun Lim ${ }^{\mathrm{b}}$, Hong-Shik Choi ${ }^{\mathrm{a}, \mathrm{c}}$ \\ ${ }^{a}$ The Institute of Logopedics and Phoniatrics, Department of Otorhinolaryngology, Gangnam Severance Hospital, Seoul, Korea \\ ${ }^{b}$ Voice Clinic, Department of Otorhinolaryngology, Gangnam Severance Hospital, Seoul, Korea \\ 'Department of Otorhinolaryngology, University College of Medicine, Seoul, Korea
}

Correspondence: Hong-Shik Choi, MD, PhD Department of Otorhinolaryngology, Yonsei University College of Medicine, 211 Eonju-ro, Gangnam-gu, Seoul 06273, Korea

Tel: +82-2-2019-3461

Fax: $+82-2-3463-4750$

E-mail: hschoi@yuhs.ac

Received: April 5, 2017

Revised: May 14, 2017

Accepted: May 17, 2017
Objectives: The purpose of this study was to confirm the responsiveness of the Korean version of the Voice Activity and Participation Profile (K-VAPP) after surgical intervention for various voice disorders and to explore the correlation between changes in the K-VAPP subscale scores and other measures, focusing on auditory-perceptual estimations. Methods: The K-VAPP was administered to 90 patients with various voice disorders who underwent surgical treatment. Along with the K-VAPP, pre- and post-operative vocal assessment results after 3 months were compared, including psychometric, acoustic (both spectral and cepstral), electroglottographic, and aerodynamic assessment. In addition, a correlation between the differences in the K-VAPP subscale scores and Grade changes of GRBAS (grade, roughness, breathiness, asthenia, strain) scale was explored. Results: After surgery, the total score, activity limitation score, and all the subscale scores except 'effect on social communication' decreased significantly. On the other hand, the participation restriction score and 'social communication' subscale score did not show significant changes. The responsiveness was supported by improvement in several psychometric, acoustic, and aerodynamic parameters, and correlation between K-VAPP subscale scores and those measures. 'Selfperceived severity' and 'effect on social communication' subscale scores showed significant correlation with perceived severity by clinician. Conclusion: In sum, the K-VAPP was confirmed to be sufficiently responsive after surgical intervention. It is clinically significant that the participation restriction and effect on social communication did not improve after surgery. Further studies pertaining to each etiological group are needed.

Keywords: Voice Activity and Participation Profile, K-VAPP, Responsiveness, Voice disorder, Surgical intervention
음성장애에 대한 중재 방향은 크게 행동적, 약물적, 또는 수술적 중재로 나눌 수 있으며, 음성장애를 유발하는 기저 질환에 따라 서 로 다른 수술적 중재가 이루어질 수 있다. 가령, 양성 성대점막 질환 환자 중 행동적 치료보다는 수술적 치료가 바람직하다고 여겨지는 경우에 대하여 기존의 외과적 수술기구를 이용한 후두미세수술 (laryngomicrosurgery, LMS) 이외에도 $\mathrm{CO}_{2}$ 레이저(Fink et al., 2016), 펄스 다이 레이저(pulse dye laser, PDL; Byeon et al., 2015; Hwang et al., 2013; Mortensen et al., 2008) 등 레이저를 이용한 LMS가 흔
히 이용되며, 최근에는 주로 비뇨기과 수술에 이용되던 인산티타 닐칼륨(potassium titanyl phosphate, KTP) 레이저가 성대 결절, 폴 립 등의 양성 성대점막 병변이나 과각화증(hyperkeratosis) 또는 백 반증(leukoplakia)의 제거뿐 아니라, 성대구증(sulcus vocalis), 성대 반흔(vocal cord scarring), 성대 암 등의 LMS에 적용되어 우수한 수술 성적이 보고되고 있다(Murono, Endo, Kondo, Wakisaka, \& Yoshizaki, 2013; Sridharan et al., 2013; Young et al., 2015).

한편, 악성 병변의 경우 똑같이 레이저를 이용한 성대 병변의 제 
거라 할지라도 음성의 질 개선 보다는 병변의 완전한 제거에 초점 을 둔 레이저 성대절제술(laser cordectomy)이 이루어진다(Fink et al., 2016). 성문폐쇄부전을 유발하는 성대마비(vocal cord palsy)에 대해서는 보형물을 삽입하여 마비측 성대를 내전시키는 갑상성형 술(thyroplasty; Buckmire, Bryson, \& Patel, 2011; Kwak, Tritter, Donovan, \& Ongkasuwan, 2016)이나, 히알루론산(hyaluronic acid, HA; Lau et al., 2010; Reiter \& Brosch, 2012; Wang et al., 2015), 자가 지방조직(Benninger, Hanick, \& Nowacki, 2016), 자가 섬유 아 세포(fibroblast; Chhetri \& Berke, 2011)와 같은 충전물을 성대근에 주입하여 성대 접촉을 개선시키는 성대주입술(injection laryngoplasty)이 널리 이루어지고 있다(Young, Smith, \& Rosen, 2013).

이러한 수술적 중재 이후의 음성의 질 변화에 대한 평가는 다양 한 양식의 평가도구들을 통해 이루어진다(Ma \& Yiu, 2011). 그 중 심리측정적 평가도구로는 음성장애지수(Voice Handicap Index, $\mathrm{VHI}$ )가 가장 널리 이용되며(Kim et al., 2007; Yun, Kim, Son, \& Choi, 2008), KVHI 외에 최근 한국어로 번안되어 타당도와 신뢰도 가 검증된 도구로서 음성 활동 및 참여 프로파일-한국판(K-VAPP) 이 있다(Lee et al., 2016). K-VAPP는 KVHI와는 달리 국제기능장애 건강 분류(International Classification of Functioning, Disabilities, and Health, ICF)의 틀에 입각하여 음성장애의 활동과 참여 측면에서의 영향을 따로 측정할 수 있는 장점이 있다. 음성장애 영 역에서 음성 활동 제한은 ‘음성 활동들에 가해지는 제한들’이며, 참여 제약은 '어떤 사람이 음성 활동을 실제로 줄이거나 피하는 것' 을 의미하는데(Ma \& Yiu, 2001), 양자 간의 격차는 임상에서 가장 적절한 중재접근법을 결정하는 데 활용될 수 있다(Lee et al., 2016).

$\mathrm{K}-\mathrm{VAPP}$ 는 VHI와 마찬가지로 환자의 자기보고에 의해 이루어지 며, 총 28 개의 문항과 5 개의 하위영역으로 이루어져 있으며, 하위영 역은 1. 목소리 문제의 심각한 정도에 대한 본인의 인식, 2. 직업에 대한 영향, 3. 일상 의사소통에 대한 영향, 4. 사회적 의사소통에 대 한 영향, 5 . 본인의 감정에 대한 영향이다. 하위영역 $2,3,4$ 의 경우 활 동 제한과 참여 제약을 묻는 10 개 쌍의 문항들로 구성된다. 총점은 280점 만점이며, 총점 이외에도 활동 제한 점수(100점 만점)와 참 여 제약 점수(100점 만점)가 별도로 산출된다(Lee et al., 2016).

그러나, 아직 K-VAPP가 수술적 중재를 요하는 음성장애에서 수 술 후 진전 정도를 적절하게 반영하는지, 더 나아가서는 이러한 음 성 관련 프로파일의 변화가 기존의 심리측정적 평가도구에서 측정 되던 변화에 비해 어떤 차별적 정보를 줄 수 있는지에 대한 연구는 전무한 실정이다. 한국어판 음성장애지수(Korean-Version of Voice Handicap Index, KVHI; Kim et al., 2007)의 경우, 레이저를 이용한 LMS (Hartl, Laoufi, \& Bransnu, 2015), 성대주입술(Wang et al., 2015), 보툴리늄 독소 주입술(Yun, Kim, Choi, \& Choi, 2011) 전후 비교 연구들에서 대부분 총점을 비롯한 모든 하위영역에서 개선된 점수가 보고되어 왔다. 그러나, 이를 통해서는 단순히 ‘음성 장애로 인한 환자의 주관적 핸디캡이 감소하였다'는 것 외에는 환 자의 음성 활동과 그에 대한 참여의 어느 부분에 더욱 개선이 필요 하다고 느끼는지, 특히 단기간에 현저한 음성 개선이 어려운 경우 추후장기적인 중재에 있어 어떠한 부분에 역점을 두어야 하는지에 대한 정보를 얻기는 어렵다.

한편, VAPP의 다른 언어 버전 연구들에서는 보다 상세한 변화 양상이 보고되어 왔다. 가령 이탈리아어 버전의 연구에서는 수술 적, 행동적, 약물적 치료 후 하위영역 4 (사회적 의사소통에 대한 영 향)의 점수를 제외하고 유의하게 점수가 감소된 반면, $\mathrm{VHI}$ 의 경우 총점과 모든 하위영역점수에서 감소를 보고하였다(Fava, Paolillo, Oliveira, \& Behlau, 2015). 핀란드어 버전 연구에서는 음성치료 후 '직업에 대한 영향' 하위영역을 제외하고는 점수가 감소되었으며, 치료 시작 1 년 후까지 음성치료가 장기적인 효과가 있음을 밝혔다

(Kleemola, Helminen, Rorarius, Sihvo, \& Isotalo, 2011).

심리측정적 평가 이외에도 청지각적 평가, 음향학적 평가, 공기역 학적 평가 등의 객관적, 주관적 평가들을 시행함으로써 음성의 상 태를 보다 종합적으로 평가할 수 있으며, 임상에서는 이렇게 다양 한 평가양식을 이용한 다면적 평가가 권고된다(Ma \& Yiu, 2006). 이에, 앞서 언급된 대부분의 수술 전후음성 비교 연구들에서는 이 와 같은 다면 평가가 활용되고 있으며, 아직 반응도가 확립되지 못 한 K-VAPP의 경우 역시 다른 양식을 이용한 수술 전후 비교가 병 행됨과 동시에, 각 측정치의 변화량들 간의 상관관계가 분석되어 야만 그 반응도가 입증될 수 있으리라고 본다. 또한, 음성장애의 심 리측정적 평가결과와 청지각적 평정치의 상관관계에 대해서는 서 로 상반된 연구결과들이 보고되어 왔다(Kim \& Choi, 2009). 만약, 수술 후 K-VAPP점수의 변화량 중에서 특히 청지각적 평가결과의 변화량과 상관관계가 깊은 점수를 탐색하여 선정할 수 있다면, 이 러한 상관관계를 뒷받침하는 근거가 될 수 있을 것이며, K-VAPP의 반응도가 더욱 구체적인 근거를 얻게 되고, 임상에서의 활용도 또 한 더욱 높아질 것으로 판단된다.

이에, 본 연구에서는 음성장애의 수술적 중재에 대한 ‘음성 활동 및 참여 프로파일-한국판(Korean version-Voice Activity \& Participation Profile, K-VAPP)'의 반응도를 측정하고, 이를 음향학적, 청지 각적, 공기역학적 및 전기성문파형검사 측정치의 변화와 함께 살펴 봄으로써 확인하고자 하였다. 또한, 이러한 다면적 검사의 측정치 중 유의한 변화를 보인 변수들의 변화량과 K-VAPP 하위점수의 수술 후 변화량 간의 상관관계를 분석하고, 하위점수 중 청지각적 평정치 
의 변화량과 유의한 상관관계를 보이는 변수를 탐색하고자 하였다.

\section{연구방법}

\section{연구대상}

$G^{*}$ Power (Faul, Erdfelder, Buchner, \& Lang, 2009)를 이용하여 수술 전후 비교(윌콕슨 부호순위 검정, Wilcoxon signed-rank test) 를 위해 충분한 최소 표본수를 산정한 결과 88 명이었다(effect size $=.4$, Power =.95). 이에, 연구대상자로 2016년 6월 13일부터 2017년 1 월 4일까지 서울 소재 한 대학병원 이비인후과에 내원하여 이비인 후과 전문의에 의해 음성장애로 진단되고, 수술적 치료를 받은 만 19 세 이상의 환자 90 명(남 42 명, 여 48 명)을 선정하였다. 이때, 본원 에 내원하기 전 타 기관에서 수술 또는 행동적 치료를 받은 자, 또는 문단 읽기 시 관찰 결과 읽기 문제가 있는 것으로 판단되거나 시력 문제를 호소하는 자, 문맹 또는 무학으로 보고한 자는 제외하였다.

대상자의 평균 연령은 남성 $50.17 \pm 16.31$ 세, 여성 $47.52 \pm 14.72$ 세 로 성별 집단 간 유의한 연령 차이는 없었다 $(F=.809, p=.421)$. 직업
적 음성사용자의 비율은 남성에서 16 명, 여성에서 14 명으로 성별 집단 간 유의한 비율 차이는 없었다 $(p=.501)$. 구체적 진단명에 따 른 환자 수와수술명은 Table 1에 제시되어 있다. Boone, McFarlane, Von Berg와 Zraick (2014)에 의한 병인학적 분류에 따르면 환자의 진단명은 기질적 음성장애 43 명, 기능적 음성장애 36 명, 신경학적 음성장애 11 명 순이었다. 수술 후 검사는 수술 3 개월 후에 시행하는 것을 원칙으로 하였으며, 수술 후 경과기간은 평균 $83.88 \pm 30.58$ 일 (중위수 76일, 범위 34-193일)이었다.

\section{평가 절차 및 도구}

먼저 사전 면담 또는 의무기록 검토를 통하여 직업적 음성 사용 여부, 발병일, 음성장애 치료력 등의 정보를 수집하였다. 사전 면담 이후 대상자가 수행하는 과제는 크게 심리측정적 평가를 위한 자 기 보고식 설문지 과제와 말 과제에 대한 음성 녹음으로 나누어 진 행되었다. 먼저 심리측정적 평가로는 KVHI (Kim et al., 2007)와 KVAPP (Lee et al., 2016)를 무작위 순서로 시행하도록 하였다. 이때, 환자가 설문지에 성실하게 응답할 수 있도록 하기 위해, 환자마다

Table 1. Diagnosis and surgical treatment of the participants

\begin{tabular}{|c|c|c|c|}
\hline Etiology & Diagnosis & $\mathrm{N}$ & Surgical treatment ( $\mathrm{N}$ of cases) \\
\hline \multirow[t]{4}{*}{ Functional } & Vocal polyp, unilateral & 29 & $\begin{array}{l}\text { LMS (9) } \\
\text { LMS with KTP laser (12) } \\
\text { PDL (8) }\end{array}$ \\
\hline & Reinke's edema & 3 & $\begin{array}{l}\text { LMS with PDL (2) } \\
\text { KTP laser (1) }\end{array}$ \\
\hline & Vocal polyps, bilateral & 2 & LMS with PDL (2) \\
\hline & Vocal nodules & 2 & LMS with KTP laser (2) \\
\hline \multirow[t]{9}{*}{ Organic } & Sulcus vocalis & 15 & $\begin{array}{l}\text { Glottoplasty with PDL (9) } \\
\text { KTP laser (6) }\end{array}$ \\
\hline & Intracordal cyst & 9 & $\operatorname{LMS}(9)$ \\
\hline & Hyperkeratosis of VC & 6 & $\begin{array}{l}\text { VC stripping with KTP laser (3) } \\
\text { PDL (3) }\end{array}$ \\
\hline & VC scarring & 5 & $\begin{array}{l}\text { PDL (2) and KTP (1) glottoplasty with Restylane injection } \\
\text { LMS with PDL (1) } \\
\text { KTP laser (1) }\end{array}$ \\
\hline & Glottic cancer & 4 & $\begin{array}{l}\text { Laser cordectomy type II (1) and type IV (1) } \\
\text { Supracricoid laryngectomy (1) } \\
\text { LMS with KTP laser (1) }\end{array}$ \\
\hline & Laryngeal papilloma & 2 & $\begin{array}{l}\text { LMS with PDL (1) } \\
\text { LMS with } \mathrm{CO}_{2} \text { laser and Cidofovir injection (1) }\end{array}$ \\
\hline & Inhalation burn & 1 & LMS with KTP laser (1) \\
\hline & Contact granuloma & 1 & LMS with KTP laser (1) \\
\hline & VC atrophy & 1 & PDL glottoplasty with Restylane injection (1) \\
\hline \multirow[t]{2}{*}{ Neurogenic } & VC palsy or paresis, unilateral & 10 & Injection laryngoplasty with Restylane (10) \\
\hline & VC palsy, bilateral & 1 & Injection laryngoplasty with Restylane (1) \\
\hline Total & & 90 & \\
\hline
\end{tabular}

$\mathrm{LMS}=$ laryngomicrosurgery; $\mathrm{KTP}=$ potassium titanyl phosphate laser; $\mathrm{PDL}=$ pulse dye laser; $\mathrm{VC}=$ vocal cord. 
주관적으로 느끼는 음성 문제가 다르기 때문에 심리측정적 평가 를 시행한다는 사실을 사전에 주지시키고, KVHI의 5점 척도와 K$\mathrm{VAPP}$ 의 11점 척도에 의한 평정 방법을 구두로 간단히 설명하였다. 아울러, 보호자나 다른 사람의 주관적 견해와 무관하게 본인의 주 관적인 느낌을 토대로 설문을 시행하도록 독려하였다.

말 과제로는 모음 /아/ 연장발성 과제와 표준 문단 읽기 과제, 최 대연장발성(maximum sustained phonation, $\mathrm{MXPH}$ ) 과제, 그리고 음성효율성(voicing efficiency, VOEF) 과제를 시행하였다. 녹음 시 사운드레벨미터(Voltcraft Datalogger 322; Conrad Electronic, Hirschau, Germany)를 이용하여 주변 환경 소음은 $50 \mathrm{~dB}$ 이하로 유지 되도록 모니터링하였다. 모음 연장발성 및 표준 문단 읽기 과제에서 는 Computerized Speech Lab (CSL Model 4150B; KayPENTAX, Lincoln Park, NJ, USA)의 기기와 하위 모듈 프로그램들을 이용하 였다. 녹음을 하는 동안 마이크(SM48; SHURE, Niles, IL, USA)는 대상자의 입술로부터 직선거리 5-10 cm에 위치하고, 녹음하는 동 안 고정된 상태로 유지하였다. MXPH와 VOEF 과제의 음성 녹음 및 분석에는 Phonatory Aerodynamic System (PAS Model 6600, KayPentax) 기기 및 프로그램을 이용하였다.

모음 연장발성 과제에서는 CSL의 Multi-dimensional Voice Program (MDVP Model 5105, KayPentax)을 이용하여 $44,100 \mathrm{~Hz}$ 의 샘플링 속도로 모음 샘플을 녹음 및 분석하였다. 구체적으로는 모 음 /아/를 편안한 음도와 크기로 가급적 일정하게 4-5초 발성하도 록 하였으며, 사전에 검사자가 모델링을 1 회 제공하였다. 모음 샘플 은 MDVP에서 4초 길이 안정 구간으로 트리밍하였으며, 환자의 모 음 연장 길이가 4 초에 이르지 못할 경우 2 초 길이의 안정 구간을 수 동으로 트리밍하였다.

표준 문단 읽기 과제에서는 Real-Time EGG analysis (Model 6103, KayPentax) 하드웨어에 연결된 한 쌍의 전극을 각각 양측의 갑상 연골 표면 부위에 접촉시켜 벨크로로 고정한 후, '가을'(Kim, 2012) 문단 전체를 읽도록 하여 $44,100 \mathrm{~Hz}$ 의 샘플링 속도로 CSL 메인 프 로그램으로 녹음하였다. 이는 EGG 프로그램의 녹음 시간이 1 분으 로 제한되어 있기 때문이었으며, 1 번 채널에는 음향학적 신호가, 2 번 채널에는 EGG 신호가 녹음되었다. 이때, 대상자로 하여금 ‘책을 읽듯이 또박또박 말하기 보다는 평소 대화하는 것처럼 자연스러운 높낮이와 크기로 읽도록 독려하였으며, 마이크와의 거리 및 각도 가 적절한지 재확인한 후, 읽는 동안 일정하게 유지하도록 하였다. 녹음 후에는 제 1 저자가 Analysis of Dysphonia in Speech and Voice (ADSV Model 5109, KayPentax) 프로그램을 이용하여 두 번째 문 장(무엇보다도 산에 오를 땐 더욱 더 그 빼어난 아름다움이 느껴진 다')을 트리밍하여 별도로 저장하였다. 이때, 음성 샘플을 재생하여
청각적으로 확인하고, 시각적으로 해당 음성 부분의 스펙트로그램 과 파형상에서 onset과 offset을 정확히 확인하여 트리밍하였다.

$\mathrm{MXPH}$ 과제에서는 대상자가 PAS 기기의 손잡이를 양손으로 잡 고 마스크를 얼굴에 밀착한 상태에서 숨을 먼저 깊게 들여 마신 후 편안한 음높이와 크기로 / 아/ 모음을 최대한 길게 발성하도록 하였 다. 이때, 마스크의 윗부분을 검사자가 손으로 밀면서 완전히 밀착 되도록 하였다(Ko, Choi, Lim, \& Choi, 2015). 사전에 검사자가 1회 모델링을 제공하였으며, 피검자가 3회 반복 시행하도록 하였다. $\mathrm{VOEF}$ 과제는 대상자가 PAS 기기의 손잡이를 양손으로 잡은 상태 에서 뉴모타코그래프에 연결된 직경 $1 \mathrm{~mm}$ 일회용 플라스틱 튜브 를 마스크에 끼워 튜브 끝을 혀 위에 위치하도록 한 다음, 마스크를 $\mathrm{MXPH}$ 와 같이 얼굴에 밀착시킨 상태에서 $/ \mathrm{pa} /$ 를 한 호흡에 5 회 반 복하도록 하는 과제를 3 회 반복 시행하였다. 이때, 대상자가 사전에 방법을 정확하게 수행할 수 있을 때까지 연습 기회를 제공하였다.

\section{자료분석}

심리측정적 평가에서는 $\mathrm{K}-\mathrm{VAPP}$ 의 경우 총점(K-VAPP $\left.\mathrm{KTL}_{\mathrm{TL}}\right)$, 활동 제한 점수(activity limitation score, ALS), 참여 제약 점수(participation restriction score, PRS)를 산정하였다. 다섯 개의 하위영역 (SUB1-SUB5) 중 SUB2 (직업에 대한 영향), SUB3 (일상 의사소통 에 대한 영향), SUB4 (사회적 의사소통에 대한 영향)에 대해서는 활동 제한 항목과 참여 제약 항목의 점수를 영역별로 따로 산출한 반면(ALS2-ALS4, PRS2-PRS4), SUB1 (목소리 문제의 심각한 정도 에 대한 본인의 인식)과 SUB5 (본인의 감정에 대한 영향)은 각 하위 영역 점수만을 산정하였다. $\mathrm{KVHI}$ 의 총점 $\left(\mathrm{KVHI}_{\mathrm{TTL}}\right)$, 기능 $\left(\mathrm{KVHI}_{\mathrm{F}}\right)$, 신체 $\left(\mathrm{KVHI}_{\mathrm{P}}\right)$, 감정 $\left(\mathrm{KVHI}_{\mathrm{E}}\right)$ 영역의 하위점수를 산정하였다.

또한, 수술 후 점수에서 수술 전 점수를 감산함으로써 수술 전후 점수 변화량 $(\Delta)$ 을 산출하였다. 수술 전후의 음성 질 변화를 청지각 적으로 확인하기 위해수술 전후 모음 및 문장 샘플에 대하여 GRBAS (Hirano, 1981) 척도를 이용한 청지각 평가를 시행하였다. 이때, 2 인 의 1 급 언어재활사가 의견 합치에 이르도록 평정을 시행하였으며, 이들의 이비인후과 음성검사실 세팅에서의 음성 검사 및 치료 경력 은 각각 3 년(제 1 저자, 언어병리학 박사)과 19년(제 2 저자, 언어병리학 석사)이었다.

각 대상자의 모음 샘플과 트리밍한 문장 샘플 총 360 개(90명 $\times 2$ 종×2회)에 대해서는 MDVP 및 $\mathrm{ADSV}$ 프로그램을 이용하여 음 향학적 분석을 시행하였다. 모음 샘플에 대해서는 MDVP를 이용 하여 주파수변동률(jitter percent), 진폭변동률(shimmer percent), 소음 대 배음 비율(noise-to-harmonic ratio, NHR)을, ADSV 프로 그램을 이용하여 켑스트럼 피크 현저성(cepstral peak prominence, 
$\mathrm{CPP}$ ), $\mathrm{L} / \mathrm{H}$ 스펙트럼 비율(low/high spectral ratio, $\mathrm{L} / \mathrm{H}$ ratio)과 각 각의 표준편차를 측정하였다. 트리밍을 시행한 말 샘플에 대해서 는 $\mathrm{CPP}$ 와 $\mathrm{L} / \mathrm{H}$ ratio와 각각의 표준편차만을 측정하였다.

전체 문단 샘플에 대해서는 $\mathrm{EGG}$ 프로그램을 이용하여 접촉지 수(contact quotient, $\mathrm{CQ}$ )의 평균, 표준편차, 범위를 산정하였다. 이 때, 음도 분석의 범위는 70-1,000 Hz였으며, 분석 시 평활화(smoothing) 옵션은 'off'로 설정하였다. MXPH 모음 샘플 세 개의 발성시 간 중에서 가장 긴 발성시간(maximum phonation time, MPT)을 선택하여 측정하였으며, VOEF 샘플 중 두 번째 산출한 5 개의 /pa/ 샘플 중 가운데 세 개를 분석하여 평균 최고 성문하압(mean peak air pressure, MPAP)과 유성음 산출 시 평균 호기류율(mean airflow rate during voicing, MFPHO)을 측정하였다.

\section{통계분석}

수술 전후 모든 측정치에 대해 정규성 검정을 위한 샤피로-윌크 검정(Shapiro-Wilk's test)을 시행한 결과, 수술 전 KVHI 총점( $p=.088)$, 수술 후 $\mathrm{L} / \mathrm{H} \mathrm{ratio}$ 의 표준편차 $(p=.521)$, 수술 후 평균 $\mathrm{CQ}(p=.260)$ 및 범위 $(p=.348)$ 등 일부 변수를 제외한 대부분의 측정치가 정규 분포를 이루지 않았다 $(p<.05)$. 따라서, 수술 전후 모든 측정치는
비모수적 통계 검정 방법인 윌콕슨 부호순위 검정을 이용하여 비교 하였으며, 유의수준은 .05로 하였다. K-VAPP의 수술 전후 변화량 이 음향학적, 청지각적, 공기역학적, 전기성문파형검사 측정치의 변 화량과 갖는 상관관계를 살펴보기 위해 스피어만 상관분석(Spearman correlation analysis)을 시행하였다. 이때, 수술 전후 측정치 비 교 시 유의한 변화를 보인 변수에 한하여 상관분석을 시행하였다. 아울러 본 연구의 중점적인 관심사인 K-VAPP 점수의 수술 전후 변 화량 중에서, 다면적 평가에서 가장 중요하다고 여겨지는 청지각적 평정치 변화량과 가장 큰 상관관계를 가진 하위점수를 탐색하기 위해 K-VAPP $\mathrm{TTL}_{\mathrm{TL}}, \mathrm{ALS}, \mathrm{PRS}, \mathrm{SUB1}-\mathrm{SUB} 5$ 를 독립변수로, GRBAS의 Grade 평정치를 종속변수로 하여 단계적 회귀분석(stepwise regression analysis)를 수행하였다. 통계 프로그램은 SPSS 23.0 software (IBM-SPSS Inc., Chicago, IL, USA)를 이용하였다.

\section{연구결과}

\section{심리측정적 측정치의 변화}

수술 전후 심리측정적 평가 결과를 비교한 결과, $\mathrm{K}-V A P P_{\mathrm{TTL}}, \mathrm{ALS}$, SUB1, SUB2, SUB3, SUB5, 그리고 ALS2, ALS3, ALS4는 유의하게

Table 2. Pre- and post-surgical data of the K-VAPP and KVHI scores

\begin{tabular}{|c|c|c|c|c|c|}
\hline Subsection & Maximum score & Pre & Post & $Z$ & $p$-value \\
\hline K-VAPP $\pi L$ & 280 & $111.50(143.50)$ & $60.50(142.50)$ & -4.834 & $<.001^{* * *}$ \\
\hline ALS & 100 & $35.50(53.75)$ & $10.00(53.25)$ & -4.925 & $<.001^{* * *}$ \\
\hline PRS & 100 & $31.00(53.75)$ & $23.50(52.25)$ & -0.538 & .590 \\
\hline \multirow[t]{2}{*}{ Job } & ALS2 (20) & $10.00(15.25)$ & $2.00(12.25)$ & -4.45 & $<.001^{* * *}$ \\
\hline & PRS2 (20) & $2.00(10.00)$ & $1.50(8.25)$ & -1.051 & .293 \\
\hline \multirow[t]{2}{*}{ Daily communication } & ALS3 (60) & $19.50(37.50)$ & $6.00(34.00)$ & -4.393 & $<.001^{* * *}$ \\
\hline & PRS3 (60) & $19.00(40.00)$ & $17.50(35.25)$ & -0.835 & .404 \\
\hline \multirow[t]{2}{*}{ Social communication } & ALS4 (20) & $5.00(10.00)$ & $2.00(8.00)$ & -3.609 & $<.001^{* * *}$ \\
\hline & PRS4 (20) & $4.00(11.00)$ & $4.50(11.00)$ & -0.694 & 0.488 \\
\hline SUB1 & 10 & $7.00(5.00)$ & $2.00(6.00)$ & -6.082 & $<.001^{* * *}$ \\
\hline SUB2 & 40 & $13.00(23.00)$ & $5.50(20.25)$ & -3.787 & $<.001^{* * *}$ \\
\hline SUB3 & 120 & $41.50(75.00)$ & $26.50(68.25)$ & -3.029 & $.002^{* *}$ \\
\hline SUB4 & 40 & $8.50(20.00)$ & $9.00(18.25)$ & -1.596 & .111 \\
\hline SUB5 & 70 & $33.00(43.75)$ & $10.00(45.00)$ & -5.463 & $<.001^{* * *}$ \\
\hline $\mathrm{KVHI}_{\pi \mathrm{L}}$ & 120 & $48.00(45.25)$ & $25.50(60.25)$ & -4.949 & $<.001^{* * *}$ \\
\hline $\mathrm{KVH} \mathrm{F}_{\mathrm{F}}$ & 40 & $13.00(14.25)$ & $7.50(19.00)$ & -4.337 & $<.001^{* * *}$ \\
\hline KVHIP & 40 & $23.00(14.00)$ & $10.50(20.25)$ & -5.2 & $<.001^{* * *}$ \\
\hline $\mathrm{KVH} \mathrm{E}_{\mathrm{E}}$ & 40 & $12.50(17.25)$ & $8.00(20.00)$ & -4.179 & $<.001^{* * *}$ \\
\hline
\end{tabular}

Values are presented as median (interquartile range).

K-VAPP ${ }_{\pi \mathrm{T}}=$ total score of the Korean version of the Voice Activity and Participation Profile; $\mathrm{KVHI}=$ the Korean-version of Voice Handicap Index; ALS=activity limitation score; PRS = participation restriction score; ALS2-4= activity limitation score of the subsection II-IV; PRS2-4= participation restriction score of the subsection II-IV; SUB1-SUB5= score of the subsection $\mathrm{I}-\mathrm{V} ; \mathrm{KVH} \|_{\Pi \mathrm{L}}=$ total score of the Korean-version of Voice Handicap Index; $\mathrm{KVH} \mathrm{F}_{\mathrm{F}}=$ functional subscale score of the $\mathrm{KVH}$; $\mathrm{KVH} \mathrm{P}_{\mathrm{p}}=$ physical subscale score of the $\mathrm{KVHl} ; \mathrm{KVHI}_{\mathrm{E}}=$ emotional subscale score of the $\mathrm{KVHI}$.

${ }^{* *} p<.01,{ }^{* * *} p<.001$. 
Table 3. Pre- and post-surgical assessment results of acoustic-perceptual measures

\begin{tabular}{lcccc}
\hline Parameter & Pre & Post & $Z$ & $p$-value \\
\hline Jitter percent & $2.431(2.454)$ & $1.57(.73)$ & -2.573 & $.010^{* *}$ \\
Shimmer percent & $5.639(4.368)$ & $4.26(4.19)$ & -1.847 & .065 \\
NHR & $0.141(0.069)$ & $0.14(0.04)$ & -0.286 & .775 \\
CPP $_{S}$ & $5.112(2.378)$ & $5.62(2.35)$ & -1.547 & .122 \\
$\sigma \sigma_{\text {CPP }}$ & $3.101(1.233)$ & $3.36(0.93)$ & -1.986 & $.047^{*}$ \\
SRS $_{\text {S }}$ & $30.051(4.970)$ & $31.31(4.59)$ & -1.98 & $.048^{*}$ \\
$\sigma R_{s}$ & $9.979(1.515)$ & $9.90(1.51)$ & -0.992 & .321 \\
CPP $_{v}$ & $9.006(4.208)$ & $10.92(5.32)$ & -4.05 & $<.001^{* * *}$ \\
$\sigma C P P_{v}$ & $0.930(0.775)$ & $0.79(0.55)$ & -2.155 & $.031^{*}$ \\
SRv & $31.798(8.385)$ & $31.89(6.03)$ & -1.434 & .151 \\
$\sigma S R_{v}$ & $1.464(0.769)$ & $1.54(0.73)$ & -0.541 & .588 \\
Grade & $2.0(0.5)$ & $1.50(1.00)$ & -5.931 & $<.001^{* * *}$ \\
Rough & $1.5(0.6)$ & $1.00(1.00)$ & -5.352 & $<.001^{* * *}$ \\
Breathy & $1.5(1.0)$ & $1.00(1.13)$ & -5.834 & $<.001^{* * *}$ \\
Asthenic & $0.0(0.0)$ & $0.00(0.00)$ & -1.282 & .200 \\
Strained & $1.5(1.0)$ & $1.00(1.00)$ & -4.786 & $<.001^{* * *}$ \\
\hline
\end{tabular}

Values are presented as median (interquartile range).

$\mathrm{NHR}=$ noise-to-harmonic ratio; $\mathrm{CPP}_{\mathrm{s}}=$ cepstral peak prominence for the passage reading task; $\sigma C P P_{S}=$ standard deviations of cepstral peak prominence for the passage reading task; $S R_{S}=\mathrm{L} / \mathrm{H}$ spectral ratio for the passage reading task; $\sigma S R_{S}=$ standard deviations of the $\mathrm{L} / \mathrm{H}$ spectral ratio for the passage reading task; $\mathrm{CPP}_{v}=$ cepstral peak prominence for the vowel production task; $\sigma \mathrm{CPP}=$ standard deviations of cepstral peak prominence for the vowel production task; $\mathrm{SRv}=\mathrm{L} / \mathrm{H}$ spectral ratio for the vowel production task; $\sigma S R_{v}=$ standard deviations of the $\mathrm{L} / \mathrm{H}$ spectral ratio for the vowel production task.

${ }^{*} p<.05,{ }^{* *} p<.01,{ }^{* * *} p<.001$.

감소하였다. $\mathrm{KVH}_{\mathrm{TTL}}, \mathrm{KVHI}_{\mathrm{F}}, \mathrm{KVHI}_{\mathrm{P}}, \mathrm{KVHI}_{\mathrm{E}}$ 또한 유의하게 감소 하였다. 반면, PRS, PRS2, PRS3, PRS4와 점수 감소는 유의하지 않 았으며, SUB4의 중위수는 오히려 증가하였다(Table 2).

\section{음향학적 및 청지각적 측정치의 변화}

수술 전후 음향학적 측정치를 비교한 결과, jitter가 유의하게 감 소하였다. 켑스트럼 분석치 중에는 문장 샘플의 $\mathrm{CPP}$ 의 표준편차 와 L/H ratio, 모음의 CPP가 유의하게 증가한 반면, 모음의 CPP 표 준편차는 유의하게 감소하였다. 청지각적 측정치는 $\mathrm{A}$ 를 제외하고 G, R, B, S scale에서 유의하게 감소하였다(Table 3). 반면, shimmer, $\mathrm{NHR}$, 문장의 $\mathrm{CPP}$ 값과 $\mathrm{L} / \mathrm{H}$ ratio의 표준편차, 모음의 $\mathrm{L} / \mathrm{H}$ ratio와 표준편차, Asthenic 값의 변화량은 통계적으로 유의하지 않았다.

\section{전기성문파형검사 및 공기역학적 측정치의 변화}

수술 전후 전기성문파형검사 및 공기역학적 측정치를 비교한 결 과, 수술 후 $\mathrm{CQ}$ 관련 변수에서는 모두 유의한 변화가 없었다. 공기역 학적 측정치 중 MPT는 유의하게 증가한 반면, MPAP와 MFPHO
Table 4. Pre- and post-surgical assessment results of electroglottographic and aerodynamic measures

\begin{tabular}{lcccc}
\hline Parameter & Pre & Post & $Z$ & $p$-value \\
\hline Mean CQ $(\%)$ & $45.87(5.20)$ & $44.29(6.19)$ & -1.263 & .206 \\
CQ range (\%) & $72.23(13.43)$ & $70.05(17.86)$ & -0.927 & .354 \\
oCQ $(\%)$ & $5.35(3.20)$ & $5.40(3.49)$ & -1.005 & .315 \\
MPT (s) & $8.53(7.68)$ & $11.49(8.14)$ & -3.815 & $<.001^{* * *}$ \\
MPAP $\left(\mathrm{cmH}_{2} \mathrm{O}\right)$ & $7.60(4.58)$ & $7.05(4.81)$ & -2.143 & $.032^{*}$ \\
MFPHO (L/s) & $0.21(0.19)$ & $0.18(0.22)$ & -2.169 & $.030^{*}$ \\
\hline
\end{tabular}

Values are presented as median (interquartile range).

$\mathrm{CQ}=$ contact quotient; $\sigma=$ standard deviations; $\mathrm{MPT}=$ maximum phonation time; $\mathrm{MPAP}=$ mean peak air pressure; $\mathrm{MFPHO}=$ mean airflow rate during voicing.

${ }^{*} p<.05,{ }^{* * *} p<.001$.

는 유의하게 감소하였다(Table 4).

\section{K-VAPP 변화량과 청지각적 측정치 변화량의 상관관계}

다면적 검사들의 수술 전후 측정치 변화량들과 K-VAPP 점수의 $\Delta$ 변화량 간 상관관계를 살펴보기 위해 시행한 스피어만 상관분석 결과가 Table 5에 제시되어 있다. KVHI의 모든 하위점수 변화량은 K-VAPP의 하위점수 변화량과 유의한 양의 상관관계가 있었다. Jitter 변화량은 ALS, SUB1, SUB5의 변화량과 유의한 양의 상관관계 를 보였으며, 켑스트럼 분석치의 변화량은 K-VAPP의 총점, ALS, SUB1, SUB5와 대부분 유의한음의 상관관계를 보였다. Grade, Rough, Breathy, Strained 모두와 유의한 양의 상관관계를 보인 하위점수 는 K-VAPP의 총점, ALS, SUB1, SUB5였다. 반면, 공기역학적 측정 치의 변화량은 K-VAPP 하위점수와 유의한 상관관계가 없었다.

수술 전후 K-VAPP 변화량 중 Grade 평정치 변화량과 유의한 상 관관계를 가진 변수를 탐색하기 위해 Stepwise regression analysis 를 시행한 결과, 유의한 상관관계를 가진 변수는 $\triangle \mathrm{SUB1}(\beta=.124)$ 과 $\triangle \mathrm{SUB} 4$ ( $\beta=-.014$ )였다(Table 6). 이때, 각 변수의 VIF는 10 미만 으로 다중 공선성은 의심되지 않았다(Table 7). 두 독립변수를 포 함한 회귀모델의 $\mathrm{R}^{2}$ 는 $.330(p=.031)$ 이었다(Figure 1$)$.

\section{논의 및 결론}

본 연구에서는 음성장애의 수술적 중재 후의 변화를 K-VAPP가 감지하는 반응도를 가지고 있음을 확인하였다. 또한, 청지각적, 음 향학적, 공기역학적, 그리고 전기성문파형검사의 다양한 변수들이 음성의 질 개선을 시사하고, K-VAPP 변화량과의 상관관계를 보임 으로써, 이러한 반응도가 지지됨을 확인하였다. 아울러, 음성 평가 에서 가장 중요하다고 여겨지는 전문가의 청지각적 측정치 가운데 전반적인 중증도의 변화를 K-VAPP의 SUB1과 SUB4의 점수가 예 
Table 5. A correlation matrix between the post-operative changes $(\Delta)$ of the K-VAPP and each measure

\begin{tabular}{|c|c|c|c|c|c|c|c|c|}
\hline & $\triangle \mathrm{K}-\mathrm{VAPP} \mathrm{\pi L}$ & $\triangle \mathrm{ALS}$ & $\triangle \mathrm{PRS}$ & $\triangle S U B 1$ & $\triangle$ SUB2 & $\triangle$ SUB3 & $\triangle$ SUB4 & $\triangle$ SUB5 \\
\hline$\Delta K V H \|_{T L}$ & $.695^{* * *}$ & $.679^{* * *}$ & $.384^{* * *}$ & $.722^{* * *}$ & $.487^{* * *}$ & $.600^{* * *}$ & $.324^{* *}$ & $.725^{* * *}$ \\
\hline$\Delta K V H I_{F}$ & $.609^{* * *}$ & $.624^{* * *}$ & $.356^{* *}$ & $.619 * * *$ & $.425^{* * *}$ & $.566^{* * *}$ & $.292^{* *}$ & $.637^{* * *}$ \\
\hline$\Delta K V H \|_{P}$ & $.579^{* * *}$ & $.562^{* * *}$ & $.298^{* *}$ & $.711^{* * *}$ & $.427^{* * *}$ & $.466^{* * *}$ & $.270^{*}$ & $.608^{* * *}$ \\
\hline$\Delta K V H I_{E}$ & $.724^{* * *}$ & $.704^{* * *}$ & $.402^{* * *}$ & $.632^{* * *}$ & $.513^{* * *}$ & $.618^{* * *}$ & $.353^{* *}$ & $.755^{* * *}$ \\
\hline$\triangle$ Jitter percent & .203 & $.263^{*}$ & .030 & $.280^{* *}$ & .065 & .135 & .099 & $.232^{*}$ \\
\hline$\triangle \sigma C P P_{S}$ & $-.217^{*}$ & $-.294^{* *}$ & -.120 & $-.411^{* *}$ & -.168 & -.149 & -.192 & $-.232^{*}$ \\
\hline$\Delta \mathrm{SR}_{\mathrm{S}}$ & -.108 & -.164 & -.008 & $-.389^{* * *}$ & -.053 & -.065 & -.013 & -.139 \\
\hline$\triangle \mathrm{CPP} v$ & -.133 & -.194 & .019 & $-.346^{* *}$ & -.062 & -.058 & -.051 & -.196 \\
\hline$\triangle \sigma C P P_{v}$ & .207 & .175 & .118 & .193 & .081 & .153 & .045 & $.217^{*}$ \\
\hline$\Delta$ Grade & $.224^{*}$ & $.326^{* *}$ & -.035 & $.552^{* * *}$ & $.254^{*}$ & .116 & .047 & $.310^{* *}$ \\
\hline$\Delta$ Rough & .162 & $.257^{*}$ & -.037 & $.411^{* * *}$ & .197 & .059 & .038 & $.252^{*}$ \\
\hline$\Delta$ Breathy & $.328^{* *}$ & $.376^{* * *}$ & .052 & $.517^{* * *}$ & $.343^{* *}$ & .166 & .178 & $.378^{* * *}$ \\
\hline$\Delta$ Strained & $.254^{*}$ & $.314^{* *}$ & -.010 & $.502^{* * *}$ & .207 & .129 & .076 & $.350^{* *}$ \\
\hline$\triangle \mathrm{MPT}$ & .034 & -.077 & .139 & -.163 & -.104 & .094 & .064 & .023 \\
\hline$\triangle \mathrm{MPAP}$ & -.001 & .037 & -.058 & .156 & -.076 & -.002 & -.077 & .046 \\
\hline$\triangle \mathrm{MFPHO}$ & .067 & .100 & -.034 & .197 & .124 & .000 & -.067 & .169 \\
\hline
\end{tabular}

K-VAPP = the Korean version of the Voice Activity and Participation Profile; K-VAPP= the Korean version of the Voice Activity and Participation Profile; KVHI=the Korean-version of Voice Handicap Index; ALS= activity limitation score; PRS = participation restriction score; ALS2-4=activity limitation score of the subsection II-IV; PRS2-4= participation restriction score of the subsection II-IV; SUB1-SUB5= score of the subsection $\mathrm{I-V} ; \mathrm{KVH} \Pi_{\mathrm{mL}}=$ total score of the $\mathrm{KVH} \mathrm{I}_{;} \mathrm{KVH} \mathrm{I}_{\mathrm{F}}=$ functional subscale score of the $\mathrm{KVHI}$; $\mathrm{KVH} \mathrm{P}_{\mathrm{p}}=$ physical subscale score of the $\mathrm{KVHI} ; \mathrm{KVHI}_{\mathrm{E}}=$ emotional subscale score of the $\mathrm{KVHI} ; \sigma \mathrm{CPP} S=$ standard deviations of cepstral peak prominence for the passage reading task; $\mathrm{SR}_{\mathrm{s}}=\mathrm{L} / \mathrm{H}$ spectral ratio for the passage reading task; $\mathrm{CPP}=$ cepstral peak prominence for the vowel production task; $\sigma \mathrm{CPP}=$ standard deviations of cepstral peak prominence for the vowel production task; MPT = maximum phonation time; MPAP= mean peak air pressure; MFPHO= mean airflow rate during voicing. ${ }^{*} p<.05,{ }^{* *} p<.01,{ }^{* * *} p<.001$.

Table 6. Stepwise regression analysis of association of post-operative changes in the K-VAPP subscale scores with perceptual estimations

\begin{tabular}{lcccccc}
\hline Model & $R$ & $R^{2}$ & $R^{2}$ change & Fchange & $d f$ & $p$-value \\
\hline SSUB1 & 0.541 & 0.293 & 0.293 & 36.466 & 1,88 & $<.001^{* * *}$ \\
$\Delta$ SUB4 & 0.575 & 0.330 & 0.037 & 4.828 & 1,87 & $.031^{*}$ \\
\hline
\end{tabular}

$\triangle S U B=$ post-operative changes in the score of subsection of the Korean version of the Voice Activity and Participation Profile.

${ }^{*} p<.05,{ }^{* * *} p<.001$.

Table 7. Coefficients of regression models predicting changes in the perceptual estimations measured by the GRBAS scale

\begin{tabular}{lcccc}
\hline Model & $\beta$ & $t$ & $p$-value & VIF \\
\hline (Constant) & -0.239 & -2.979 & 0.004 & \\
$\Delta$ SUB1 & 0.124 & 6.539 & $<0.001^{* * *}$ & 1.173 \\
$\Delta$ SUB4 & -0.014 & -2.197 & $0.031^{*}$ & 1.173 \\
\hline
\end{tabular}

$\mathrm{VIF}=$ variance inflation factor; $\Delta S U B=$ post-operative changes in the score of subsection 1 and 4 of the Korean version of the Voice Activity and Participation Profile. ${ }^{*} p<.05,{ }^{* * *} p<.001$.

측한다는 것을 확인하였다.

심리측정적 평가치 가운데 K-VAPP에서는 PRS, PRS2, PRS3, PRS4와 SUB4를 제외한 모든 하위영역 점수와 총점에서 수술 후 감 소를 보인 반면, $\mathrm{KVHI}$ 의 경우 총점과 모든 하위영역 점수에서 수술

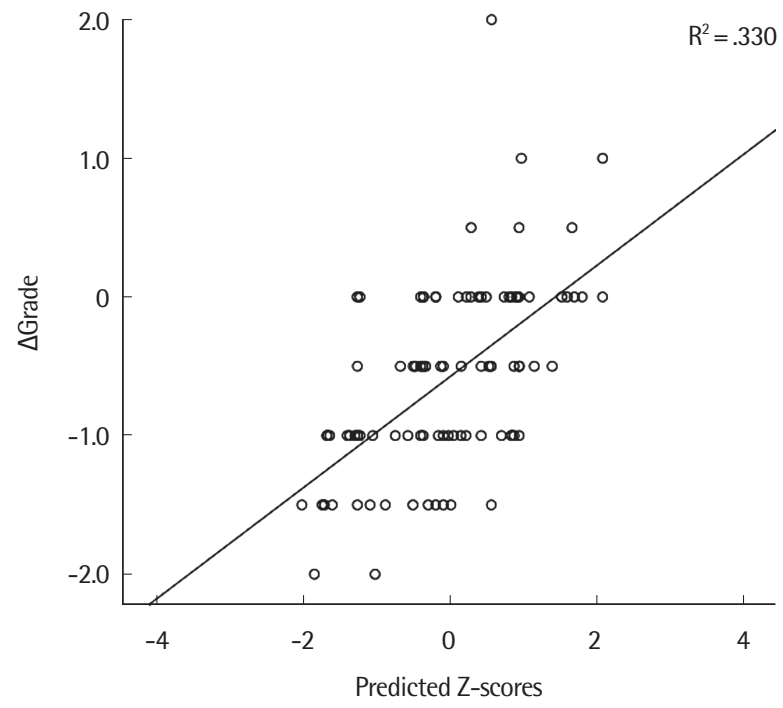

Figure 1. A scatterplot of the post-operative changes in perceptual estimations and the predicted Z-scores.

$\Delta$ Grade $=$ post-operative changes in the Grade scale.

후 감소가 나타났다. 이는 모든 하위영역점수에서 감소를 보고한 이탈리아어 표준화 연구(Fava et al., 2015), 그리고 음성치료 후 '직 업에 대한 영향' 하위영역을 제외하고는 점수가 감소된 핀란드어 버 전 연구(Kleemola et al., 2011)와 일맥상통한다. 다만, PRS, PRS2, 
PRS3, PRS4와 SUB4에서 유의한 감소가 나타나지 않은 부분은 두 선행연구와 다르다. KVHI의 모든 점수가 유의하게 감소하였음에 도 이들 하위점수가 감소하지 않은 것은 환자의 음성 활동 제한은 어느 정도 수술 후 해결이 되었으나, 직업활동, 일상생활, 사회적 의 사소통 등에서의 음성활동들에 대한 참여 제약, 특히 사회적 의사 소통 측면에서 음성 문제가 아직 해결되지 않았다고 느낌을 의미하 며, 이는 이후의 중재방향 및 성과 측정에 대해 시사점이 있다고 여 겨진다.

PRS2와 SUB4의 수술 전 검사에서의 중위수는 각각 2.0점(20점 만점)과 8.5점(40점 만점)으로 비교적 낮은 편이었다. SUB2의 경우 수술 전 점수가 낮다는 것만 생각한다면 한편으로는 참여 제약이 크지 않았다는 것으로도 해석할 수 있으나, 활동 제한이 높으면서 도 참여 제약 점수가 낮다는 것은 역설적으로 음성 사용의 불편함 이 큼에도 불구하고 참여를 줄일 수 없는 현실에 처해있다는 방증 일 수 있다. 또한, SUB4의 경우 수술 전후 유의한 차이가 없었던 것 은 수술 후 당분간 목소리 사용을 자제하는 등의 조치에 의해 사회 적 의사소통 영역에 대해 부정적 영향을 받았을 가능성을 반영하 는 것일 수 있다. 이와 같이 환자가 수술 후 개선되지 않은 부분은 연구 및 임상적 시사점이 있으며, 더욱 장기적인 추적검사를 통해 변화양상을 살펴볼 필요성 또한 대두된다.

다만, 선행연구와의 차이는 두 선행연구의 대상자의 음성질환과 사용된 중재방법, 초기 및 중재 후 추적검사 간 경과기간의 차이에 기인한 것으로 보인다. 먼저, 이탈리아어 표준화 연구에서는 행동 적, 수술적, 약물적 치료를 받은 대상자가 모두 포함되었고, 환자의 기저질환 및 병인, 그리고 초기 평가와 중재 후 평가 간 경과기간에 대한 정보가 없다(Fava et al., 2015). 이 경우 만약 초기 평가와 중재 후 평가 간 경과기간이 본 연구보다 긴 환자가 많이 포함되었다면, 시간 경과에 따라 참여 제약 점수의 감소폭이 더욱 크게 측정되었 을 가능성이 크다. 핀란드어 버전 연구의 경우 기질적 혹은 기능적 음성장애 환자가 포함되었고, 3-5 회기 음성치료를 받은 후 평가를 시행하였다는 점에서 본 연구와는 다르다(Kleemola et al., 2011). 이는 단순히 수술적 중재만 시행한 본 연구에 비해 행동적 중재를 통해 일상 생활 및 사회적 의사소통에 대한 영향을 보다 효과적으 로 감소시켰을 가능성을 배제할수 없음을 시사한다.

$\mathrm{VHI}$ 의 경우 행동적 치료 전후 비교를 통해서도 그 반응도가 입 증된 바 있으며(Bouwers \& Dikkers, 2009; Hengen, Peterson, \& McAllister, 2017; Reiter, Rommel, \& Brosch, 2013; Van Lierde, Claeys, De Bodt, \& van Cauwenberge, 2007; Zhuge, You, Wang, Zhang, \& $\mathrm{Du}, 2016), \mathrm{K}-\mathrm{VAPP}$ 를 이용하여 수술적 중재뿐 아니라 행동적 중재 를 특정하여 전후 프로파일을 비교하는 일 또한 필요할 것이다. 또
한, 성대유두종과 같이 재발률이 높아 반복적인 수술이 요구되는 질환에서 이러한 프로파일 변화가 환자의 음성 활동 제한과 참여 제약의 변화를 민감하게 확인하는 데 도움이 될 수 있을 것이다 (Loizou, Laurell, Lindquist, \& Olofsson, 2014). 또한, 갑상선절제술 (thyroidectomy) 환자의 수술 전후 비교(Lee et al., 2017; Radowsky, Helou, Howard, Solomon, \& Stojadinovic, 2013; Solomon, Awan, Helou, \& Stojadinovic, 2012; Vicente et al., 2014)를 통하여 수술 후 음성의 불편함을 호소하는 환자가 실제 수술 전에 비해 얼마나 더 욱 큰 활동 제한 및 참여 제약을 보이는 것인지 확인할 수 있을 것 으로 생각된다. 다만, 이러한 후속 연구에 있어 심리측정적 평가치 의 변화를 적절히 해석하기 위해서는 음성 활동 및 참여 프로파일 의 기초선에 영향을 미칠 수 있는 요인들 또한 충분히 고려되어야 할 것이다. 이러한 요인으로는 성별, 병인집단, 중증도, 직업적 음성 사용의 여부 혹은 수준 등을 생각할 수 있다(Dassie-Leite, Delazeri, Baldissarelli, \& Weber, 2014).

수술 후 청지각적 측정치는 A를 제외하고 $\mathrm{G}, \mathrm{R}, \mathrm{B}, \mathrm{S}$ 측정치가 감 소하여 청지각상 음성의 질이 개선되었음을 시사하였다 jitter의 감 소, 모음의 $\mathrm{CPP}$ 증가, 문장의 $\mathrm{L} / \mathrm{H}$ ratio 증가 등의 음향학적 측정치 변화와 $\mathrm{MPT}$ 증가, $\mathrm{MFPHO}$ 감소 등의 공기역학적 측정치 변화 또 한 수술 후 음성의 질 개선을 뒷받침하였다. 반면, 수술 후 CQ 관련 변수에서는 유의한 변화가 없었는데, 이는 수술 전 음성질환의 이질 성에 기인한 것으로 보인다. 가령, 성문폐쇄부전을 보이는 성대마비 등의 질환에서는 $\mathrm{CQ}$ 가 증가하였으나, 다른 한편으로 성대접촉을 도모하기 위한 가성대의 보상적 노력이나 병변으로 인해 CQ가 수 술 전 이미 증가되었던 경우 오히려 수술 후 $\mathrm{CQ}$ 가 감소되었을 가능 성을 배제할 수 없다. 즉, 이러한 이질성이 실제 수술 전후의 음성관 련 변수의 개선 효과를 희석시켰을 수 있는 것이다. 따라서, 단순히 $\mathrm{K}-\mathrm{VAPP}$ 의 반응도를 살펴보는 것이 아니라 특정 중재의 효과를 정 확하게 검증하기 위해서는 보다 단일한 특성을 가진 특정 질환군 을 대상으로 한 후속 연구들이 이루어져야만 할 것으로 여겨진다.

$\mathrm{KVHI}$ 의 변화량은 K-VAPP의 변화량과 유의한 양의 상관관계 가 있었으며, 이는 KVHI와의 높은 공인타당도를 보고한 선행연구 결과와 일맥상통한다(Lee et al., 2016). 전통적인 시간기반 분석과 켑스트럼 분석 결과뿐만 아니라 청지각적 측정치의 변화량과 공통 적으로 유의한 상관관계를 보인 K-VAPP 하위점수 변화량은 ALS, SUB1, SUB5의 변화량이었으며, 이는 음성장애에 대한 중재 전후 의 K-VAPP 프로파일 변화를 살펴볼 때, 여러 하위점수 중에서도 해당 하위점수들을 특히 주목하여야 할 필요성을 시사한다. 반면, 공기역학적 측정치의 변화량은 K-VAPP 하위점수와 유의한 상관 관계가 없었는데, 발성 시 호흡의 효율적인 사용이 개선된다고 해 
서 주관적인 음성장애의 정도가 반드시 함께 감소하지는 않는다는 것이다. 이러한 점은 수술에 의한 구조적 변화에 따라 호흡 활용이 보다 효율적으로 개선되는 것과 더불어, 일상생활에서의 이러한 호 흡 능력 개선을 활용할 수 있는 추가적인 음성치료의 필요성을 시 사할 수 있다고 본다.

청지각적 측정치인 전반적 중증도의 변화를 예측하는 K-VAPP 하위점수로 SUB1과 SUB4의 점수가 있었다. SUB1의 경우, 음성장 애 중증도에 대한 환자 스스로의 인식 변화량이 전문가의 청지각 평가 변화량과 일정 정도 상관관계를 보였다는 것이다. 사실, 많은 선행연구들에서는 대상자 스스로의 중증도 인식 혹은 삶의 질 척 도는 전문가의 청지각 평가 또는 음향학적 평가결과, 전기성문파형 검사와 상관관계가 없거나(Awan, Roy, \& Cohen, 2014; Kankare, Liu, Laukkanen, \& Geneid, 2013), 상관관계가 있더라도 강하지는 않다(Murry, Medrado, Hogikyan, Aviv, 2004).

그럼에도 불구하고 본 연구에서 유의한 양의 상관관계가 나타난 것은 아래 세 가지 이유로 설명될 수 있다. 첫째, 본 연구에서는 상 관관계가 없다고 보고된 선행연구와는 달리, 특정 시점에서의 주관 적 음성장애 중증도와 청지각 평정치 간의 상관관계가 아니라, 중 재 후 각각의 변화량 간의 상관관계를 살펴본 것이었기 때문이다. 둘째, SUB1에 해당하는 문항이 본인의 중증도 인식을 묻는 단순명 확한 질문 한 개('본인의 목소리 문제는 얼마나 심각합니까?')로 이 루어져 있기 때문인 것으로 보인다. 셋째, 0 점에서 10 점에 이르기까 지 평정하도록 하는 비교적 친숙하고(Ma \& Yiu, 2007), 아울러 시 행이 용이한(Pires, Oliveira, \& Behlau, 2011) 11점 척도가 여타 5점 척도 등에 비해 답변이 보다 잘 이산(dispersion)되도록 함으로써 답변의 신뢰도와 타당도를 높이는 데 중요한 역할을 했을 가능성 (Dawes, 2002)이 있다.

반면 하위영역 4 (사회적 의사소통에 대한 영향)의 변화량은 음 의 비표준화 계수를 가짐으로서 청지각적 평가의 변화량과 서로 반비례함을 알 수 있었다. 이러한 결과가 나타난 데에는 다양한 병 인의 환자들이 혼재된 것이 일정 부분 역할을 했을 것으로 보인다. 가령, 성대암 환자의 경우 수술적 중재의 목적이 음성의 질 개선이 라 하기 보다는 암 조직의 제거 및 재발 방지로 단기의 추적 검사를 통해 살펴 보아서는 사회적 의사소통에 이르기까지는 긍정적인 효 과가 미치지 않았을 수 있으며, 이러한 점이 사회적 의사소통에 대 한 영향'의 변화에 반영되었을 수 있다. 특히, 음성 문제를 주소로 내원하여 암이 발견된 것이 아니라, 음성 문제가 없이 건진 등을 통 해 암이 발견되어 수술이 이루어진 경우, 주관적 음성장애 중증도 가 크게 증가하는 임상 사례들이 많으며, 본 연구에 포함된 성문암 환자의 경우도 대부분 그러하다. 따라서, 보다 단일한 질환의 환자
군에 대하여 장기간에 걸친 추적검사를 통해 음성활동 및 참여 프 로파일의 변화를 살펴볼 필요가 있으며, 이러한 필요성은 후두암 환자에 대한 5 년 이상 장기간의 추적검사에서 삶의 질의 향상이 보 고된 선행연구에 의해 뒷받침된다(Valls-Mateus et al., 2016). 또한, 수술적 중재 후 일정 기간 음성 사용을 제한하는 점 역시 이러한 부분에 일정 부분 영향을 미쳤을 것으로 보인다.

본 연구는 다양한 병인을 지닌 음성장애 환자들을 대상으로 KVAPP의 반응도를 단순히 수술 전후 비교를 통해 본 것이 아니라, 다면적 음성검사 측정치들과 함께 확인하여 검증하였다는 데 의의 가 있다. 그러나, 병인과 음성장애의 정도, 적용된 수술적 중재 방법 이 서로 이질적인 환자들이 모두 포함되었다는 한계가 매우 명확하 다. 따라서, 후속 연구에서는 먼저 병인집단에 따른 프로파일의 기 초선을 구축함과 동시에, 특정 병인집단에 대하여 적절한 수술적 중재방법을 선택하여 수술 전후 프로파일 변화를 살펴봄으로써 임상에서의 유용성을 더할 수 있을 것으로 보인다. 또한, 청지각적 평가 방법으로 GRBAS에 비해 자료를 잘 이산시킬 수 있고 ASHA 에 의해 임상 및 연구에서 권고되는 CAPE-V (Consensus AuditoryPerceptual Evaluation of Voice; Kempster, Gerratt, Abbott, Barkmeier-Kraemer, \& Hillman, 2009) 등을 이용한다면 더욱 의미 있 는 결과가 도출될 수 있으리라 본다.

\section{REFERENCES}

Awan, S. N., Roy, N., \& Cohen, S. M. (2014). Exploring the relationship between spectral and cepstral measures of voice and the Voice Handicap In$\operatorname{dex}(\mathrm{VHI})$. Journal of Voice, 28, 430-439.

Benninger, M. S., Hanick, A. L., \& Nowacki, A. S. (2016). Augmentation autologous adipose injections in the larynx. Annals of Otology, Rhinology \& Laryngology, 125, 25-30.

Boone, D. R., McFarlane, S. C., Von Berg, S. L., \& Zraick, R. I. (2014). The voice and voice therapy (9th ed.). Boston, MA: Pearson.

Bouwers, F., \& Dikkers, F. G. (2009). A retrospective study concerning the psychosocial impact of voice disorders: Voice Handicap Index change in patients with benign voice disorders after treatment (measured with the Dutch version of the VHI). Journal of Voice, 23, 218-224.

Buckmire, R. A., Bryson, P. C., \& Patel, M. R. (2011). Type I Gore-Tex laryngoplasty for glottic incompetence in mobile vocal folds. Journal of Voice, $25,288-292$.

Byeon, H. K., Han, J. H., Choi, B. I., Hwang, H. J., Kim, J. H., \& Choi, H. S. (2015). Treatment of hemorrhagic vocal polyps by pulsed dye laser-assist- 
ed laryngomicrosurgery. BioMed Research International, 2015, 1-6.

Chhetri, D. K., \& Berke, G. S. (2011). Injection of cultured autologous fibroblasts for human vocal fold scars. The Laryngoscope, 121, 785-792.

Dassie-Leite, A. P., Delazeri, S., Baldissarelli, B., \& Weber, J. (2014). Vocal selfassessment: relation with the type of instrument, gender, age, and profession in individuals without vocal complaints. CoDAS, 26, 531-534.

Dawes, J. (2002). Five point vs. eleven point scales: does it make a difference to data characteristics. Australasian Journal of Market Research, 10, 39-47.

Faul, F., Erdfelder, E., Buchner, A., \& Lang, A. G. (2009). Statistical power analyses using $G^{\star}$ Power 3.1: tests for correlation and regression analyses. Behavior Research Methods, 41, 1149-1160.

Fava, G., Paolillo, N. P., Oliveira, G., \& Behlau, M. (2015). Cross-cultural adaptation, validation, and cutoff point of the Italian version of the voice activity and participation profile: Profilo di Attività e Partecipazione Vocale. Journal of Voice, 29, 130-e11.

Fink, D. S., Sibley, H., Kunduk, M., Schexnaildre, M., Kakade, A., Sutton, C., \& McWhorter, A. J. (2016). Subjective and objective voice outcomes after transoral laser microsurgery for early glottic cancer. The Laryngoscope, 126, 405-407.

Hartl, D. M., Laoufi, S., \& Brasnu, D. F. (2015). Voice outcomes of transoral laser microsurgery of the larynx. Otolaryngologic Clinics of North America, $48,627-637$.

Hengen, J., Peterson, M., \& McAllister, A. (2017). Patient characteristics and intervention effect as measured by Voice Handicap Index. Logopedics Phoniatrics Vocology, 42, 93-98.

Hirano, M. (1981). Clinical examination of voice. New York, NY: Springer.

Hwang, C. S., Lee, H. J., Ha, J. G., Cho, C. I., Kim, N. H., Hong, H. J., \& Choi, H. S. (2013). Use of pulsed dye laser in the treatment of sulcus vocalis. Otolaryngology-Head and Neck Surgery, 148, 804-809.

Kankare, E., Liu, D., Laukkanen, A. M., \& Geneid, A. (2013). EGG and acoustic analyses of different voice samples: comparison between perceptual evaluation and voice activity and participation profile. Folia Phoniatrica et Logopaedica, 65, 98-104.

Kempster, G. B., Gerratt, B. R., Abbott, K. V., Barkmeier-Kraemer, J., \& Hillman, R. E. (2009). Consensus auditory-perceptual evaluation of voice: development of a standardized clinical protocol. American Journal of SpeechLanguage Pathology, 18, 124-132.

Kim, H. (2012). Neurologic speech-language disorders. Seoul: Sigma Press.

Kim, J., \& Choi, H. S. (2009). Comparison of clinicians' perceptual evaluations and patients' subjective evaluations of voice disorders. Korean Jour- nal of Communication Disorders, 14, 223-235.

Kim, J., Lim, S. E., Park, S. Y., Choi, S., Choi, J. N., \& Choi, H. S. (2007). Validity and reliability of Korean-Version of Voice Handicap Index and VoiceRelated Quality of Life. Speech Science, 14, 111-125.

Kleemola, L., Helminen, M., Rorarius, E., Sihvo, M., \& Isotalo, E. (2011). Twelvemonth clinical follow-up study of voice patients' recovery using the Voice Activity and Participation Profile (VAPP). Journal of Voice, 25, e245-e254.

Ko, H., Choi, H. S., Lim, S. E., \& Choi, Y. (2015). Comparison of aerodynamic variables according to the execution methods of KayPENTAX Phonatory Aerodynamic System Model 6600. Phonetics and Speech Sciences, 7, 93-99.

Kwak, P. E., Tritter, A. G., Donovan, D. T., \& Ongkasuwan, J. (2016). Longterm voice outcomes of early thyroplasty for unilateral vocal fold paralysis following aortic arch surgery. Annals of Otology, Rhinology \& Laryngology, $125,559-563$.

Lau, D. P., Lee, G. A., Wong, S. M., Lim, V. P., Chan, Y. H., Tan, N. G., ... \& Morrison, M. D. (2010). Injection laryngoplasty with hyaluronic acid for unilateral vocal cord paralysis: randomized controlled trial comparing two different particle sizes. Journal of Voice, 24, 113-118.

Lee, D. Y., Lee, K. J., Hwang, S. M., Oh, K. H., Cho, J. G., Baek, S. K., ... \& Jung, K. Y. (2017). Analysis of temporal change in voice quality after thyroidectomy: single-institution prospective study. Journal of Voice, 31, 195-201.

Lee, S. J., Choi, H. S., Kim, H., Byeon, H. K., Lim, S. E., \& Yang, M. K. (2016). Korean version of the Voice Activity and Participation Profile (K-VAPP): a validation study. Communication Sciences \& Disorders, 21, 695-708.

Loizou, C., Laurell, G., Lindquist, D., \& Olofsson, K. (2014). Voice and quality of life in patients with recurrent respiratory papillomatosis in a northern Sweden cohort. Acta Oto-laryngologica, 134, 401-406.

Ma, E. P., \& Yiu, E. M. (2006). Multiparametric evaluation of dysphonic severity. Journal of Voice, 20, 380-390.

Ma, E. P., \& Yiu, E. M. (2007). Scaling voice activity limitation and participation restriction in dysphonic individuals. Folia Phoniatrica et Logopaedica, 59, 74-82.

Ma, E. P., \& Yiu, E. M. (2001). Voice activity and participation profile: assessing the impact of voice disorders on daily activities. Journal of Speech, Language, and Hearing Research, 44, 511-524.

Ma, E. P., \& Yiu, E. M. (2011). Handbook of voice assessments. San Diego, CA: Plural Pub.

Mortensen, M. M., Woo, P., Ivey, C., Thompson, C., Carroll, L., \& Altman, K. (2008). The use of the pulse dye laser in the treatment of vocal fold scar: a 
preliminary study. The Laryngoscope, 118, 1884-1888.

Murono, S., Endo, K., Kondo, S., Wakisaka, N., \& Yoshizaki, T. (2013). Oncological and functional outcome after transoral 532-nm pulsed potassiumtitanyl-phosphate laser surgery for T1a glottic carcinoma. Lasers in Medical Science, 28, 615-619.

Murry, T., Medrado, R., Hogikyan, N. D., \& Aviv, J. E. (2004). The relationship between ratings of voice quality and quality of life measures. Journal of Voice, 18, 183-192.

Pires, M. D. E., Oliveira, G., \& Behlau, M. (2011). Voice Activity and Participation Profile (VAPP) administered in two different scales of response. Jornal da Sociedade Brasileira de Fonoaudiologia, 23, 297-300.

Radowsky, J. S., Helou, L. B., Howard, R. S., Solomon, N. P., \& Stojadinovic, A. (2013). Racial disparities in voice outcomes after thyroid and parathyroid surgery. Surgery, 153, 103-110.

Reiter, R., Rommel, D., \& Brosch, S. (2013). Long term outcome of psychogenic voice disorders. Auris Nasus Larynx, 40, 470-475.

Rudolf, R., \& Sibylle, B. (2012). Laryngoplasty with hyaluronic acid in patients with unilateral vocal fold paralysis. Journal of Voice, 26, 785-791.

Solomon, N. P., Awan, S. N., Helou, L. B., \& Stojadinovic, A. (2012). Acoustic analyses of thyroidectomy-related changes in vowel phonation. Journal of Voice, 26, 711-720.

Sridharan, S., Achlatis, S., Ruiz, R., Jeswani, S., Fang, Y., Branski, R. C., \& Amin, M. R. (2014). Patient-based outcomes of in-office KTP ablation of vocal fold polyps. The Laryngoscope, 124, 1176-1179.

Valls-Mateus, M., Ortega, A., Blanch, J. L., Sabater, F., Bernal-Sprekelsen, M., \& Vilaseca, I. (2016). Long-term quality of life after transoral laser microsurgery for laryngeal carcinoma. Journal of Surgical Oncology, 114, 789795.

Van Lierde, K. M., Claeys, S., De Bodt, M., \& Van Cauwenberge, P. (2007).
Long-term outcome of hyperfunctional voice disorders based on a multiparameter approach. Journal of Voice, 21, 179-188.

Vicente, D. A., Solomon, N. P., Avital, I., Henry, L. R., Howard, R. S., Helou, L. B., ... \& Shaha, A. R. (2014). Voice outcomes after total thyroidectomy, partial thyroidectomy, or non-neck surgery using a prospective multifactorial assessment. Journal of the American College of Surgeons, 219, 152-163.

Wang, C. C., Chang, M. H., Jiang, R. S., Lai, H. C., De Virgilio, A., Wang, C. P., ... \& Liang, K. L. (2015). Laryngeal electromyography-guided hyaluronic acid vocal fold injection for unilateral vocal fold paralysis: a prospective long-term follow-up outcome report. JAMA Otolaryngology-Head \& Neck Surgery, 141, 264-271.

Young, V. N., Mallur, P. S., Wong, A. W., Mandal, R., Staltari, G. V., GartnerSchmidt, J., \& Rosen, C. A. (2015). Analysis of potassium titanyl phosphate laser settings and voice outcomes in the treatment of Reinke's edema. Annals of Otology, Rhinology \& Laryngology, 124, 216-220.

Young, V. N., Mallur, Smith, L. J., \& Rosen, C. A. (2013). Voice outcome following acute unilateral vocal fold paralysis. Annals of Otology, Rhinology \& Laryngology, 122, 197-204.

Yun, B., Kim, H., Choi, Y., \& Choi, H. S. (2011). Voice characteristics of adductor spasmodic dysphonia before and after botulinum toxin-A injection. Korean Journal of Otorhinolaryngology-Head Neck Surgery, 54, 148153.

Yun, Y. S., Kim, H. H., Son, Y. I., \& Choi, H. S. (2008). Validation of the Korean Voice Handicap Index (K-VHI) and the clinical usefulness of Korean VHI-10. Korean Journal of Communication Disorders, 13, 216-241.

Zhuge, P., You, H., Wang, H., Zhang, Y., \& Du, H. (2015). An analysis of the effects of voice therapy on patients with early vocal fold polyps. Journal of Voice, 30, 698-704. 


\section{국문초록}

\section{수술적 중재 후 음성 활동 및 참여 프로파일-한국판(K-VAPP)의 반응도 연구}

이승진 ${ }^{1}$ 임성은 ${ }^{2} \cdot$ 최홍식 ${ }^{1,3}$

1강남세브란스병원 이비인후과 후두음성언어의학연구소, ${ }^{2}$ 강남세브란스병원 이비인후과 언어치료실, ${ }^{3}$ 연세대학교 의과대학 이비인후과학교실

배경 및 목적: ‘음성 활동 및 참여 프로파일-한국판(K-VAPP)'는 타당도 및 신뢰도 측면에서 검증되었으나, 중재 후의 반응도는 아직 연 구되지 않았다. 이에, 본 연구에서는 다양한 음성장애 환자의 수술적 중재에 대한 K-VAPP의 반응도를 검증하였다. 방법: 다양한 병인 의 음성장애에 대하여 수술적 중재를 받고 수술 전 및 수술 3 개월 후 음성검사를 시행한 환자 90 명을 대상으로 하였다. 심리측정적 평 가로 $\mathrm{K}-\mathrm{VAPP}$ 와 $\mathrm{KVHI}$ 를, 청지각적 평가로 $\mathrm{GRBAS}$ 를, 음향학적 검사로 $\mathrm{MDVP}$ 및 $\mathrm{ADSV}$ 를 시행하였으며, $\mathrm{EGG}$ 와 PAS로 측정된 성대 접촉지수 및 공기역학적 측정치를 비교하였다. K-VAPP 하위점수가 다른 측정치와 갖는 상관관계를 분석하고, Grade 변화량과 상관관 계가 큰 하위점수를 탐색하였다. 결과: 수술 후 K-VAPP의 총점, 활동 제한 점수와 ‘목소리 문제의 심각한 정도에 대한 본인의 인식', '직 업에 대한 영향', ‘일상 의사소통에 대한 영향', ‘본인의 감정에 대한 영향’ 점수가 유의하게 감소하였다. 반면, 참여 제약 점수와 '사회적 의사소통에 대한 영향’ 점수는 차이가 없었다. 이러한 반응도는 여타 음향학적, 공기역학적 변수의 술 전후 개선과 변화량 간 상관관계 에 의해 뒷받침되었다. Grade 변화량과 상관관계가 큰 변화량을 보인 하위영역은 1 과 4 였다. 논의 및 결론: K-VAPP는 충분한 수준의 반응도를 보였다. 음성의 질이 개선되었음에도 참여 제약 및 사회적 의사소통 영역 점수가 개선되지 않은 점은 장기적인 중재 차원에서 임상적 시사점이 있으며, 각각의 병인집단 또는 수술에 대한 후속연구가 필요할 것으로 보인다.

핵심어: 음성 활동 및 참여 프로파일-한국판, K-VAPP, 반응도, 음성장애, 수술적 중재

\section{참고문헌}

고혜주, 최홍식, 임성은, 최예린(2015). KayPENTAX Phonatory Aerodynamic System Model 6600의 수행방법에 따른 공기역학 변수 비교. 말소리와 음성과학, 7, 93-99.

김재옥, 임성은, 박선영, 최성희, 최재남, 최홍식(2007). 한국어판 음성장애지수와음성관련 삶의 질의 타당도 및 신뢰도 연구. 음성과학, 14, 111-125. 김재옥, 최홍식(2009). 평가자의 청지각적 음성평가와 대상자의 주관적 음성평가 비교. 언어청각장애연구, 14, 223-235.

김향희(2012). 신경언어장애. 서울: 시그마프레스.

윤보람, 김향희, 최예린, 최홍식(2011). 내전형 연축성 발성장애 환자의 보툴리눔 독소-A 주입술 전후의 음성특성 비교. 대한이비인후과학회지 두경 부외과학, 54, 148-153.

윤영선, 김향희, 손영익, 최홍식(2008). 한국어판 음성장애지수(Voice Handicap Index, VHI)의 타당도 및 VHI-10의 임상적 유용성. 언어청각장애연 구, 13, 216-241.

이승진, 최홍식, 김향희, 변형권, 임성은, 양민교(2016). 음성 활동 및 참여 프로파일-한국판(K-VAPP): 타당성 검증 연구. 언어청각장애연구, 21, 695708. 